\title{
Shadow Exchange Rates - Changing the Winds with Headwinds and Tailwinds
}

https://doi.org/10.21272/sec.3(2).78-88.2019

\section{Masaaki Yoshimori}

Former Fellow, James A. Baker III Institute, Rice University, USA

\section{Abstract}

This paper summarizes the arguments and counterarguments within the academic discussion on the issue of double exchange rates - official exchange rates and unofficial exchange rates - produced by the cryptocurrency bitcoin (BTC). The policy conclusion of this research is that cryptocurrency exchange rates ought to be monitored by authorized organizations because of unsustainable price volatility. The relevance of the decision of this scientific problem is that some unofficial exchange rates are likely to have higher volatility caused by BTC's bubble and burst than by the official exchange rate.

Methodological tools of the research methods are the event window study which is to measure the abnormal response of an asset price. Through investors' psychology, I analyze the bubble and burst mechanism of BTC. The big factor ignored by cryptocurrency supporters is that people do need to use "fiat currencies" -- the significant issue is that the coins are not issued or managed by any governments, although "the progress of fintech" is a welcome innovation.

Overall, the paper presents the finding of experts and empirical results, which can help build a more sustainable financial market. The recommendations of this paper can be useful for policy makers, regulators, and academics.

Keywords: burst and bubble, cryptocurrency, fiat currency, exchange rate.

JEL Classification: F31, G00, K24.

Cite as: Yoshimori, M. (2019). Shadow Exchange Rates - Changing the Winds with Headwinds and Tailwinds. SocioEconomic Challenges, 3(2), 78-88. https://doi.org/10.21272/sec.3(2).78-88.2019.

(C) The Author, 2019. This article is published with open access at Sumy State University.

"I wonder how much it would take to buy a soap bubble, if there were only one in the world." (Mark Twain)

\section{Introduction}

Fintech companies have been established recently with billion-dollar investments ${ }^{1}$. With progressing technological, cryptocurrencies ${ }^{2}$ (i.e. virtual currencies) have appeared and expanded. Some currency markets have platforms, where investors trade on a speculative basis against real-world currencies (Kim, 2015). The ethereum platform ${ }^{3}$ provides investors with 1162 digital currencies as of May 2019. By far the cryptocurrency with the largest market capitalization is bitcoin (BTC).

\footnotetext{
${ }^{1}$ A recent report by Citigroup suggests that total fintech investment quadrupled between 2010 and 2015 to about $\$ 19$ billion annually (See Citi GPS (2016)). Mckinsey \& Company estimates over 2,000 fintech startups. (See Dietz, Khanna, Olanrewaju, and Rajgopal (2016).)

${ }^{2}$ Cryptocurrencies by Market Capitalization (March 13, 2019).

\begin{tabular}{|l|c|c|}
\hline \multicolumn{1}{|c|}{ Cryptocurrency Name } & Market Capitalization (USD) & Price (USD) \\
\hline Bitcoin & $\$ 72,377,686,824$ & $\$ 3,914.69$ \\
\hline XRP & $\$ 14,052,759,890$ & $\$ 133.55$ \\
\hline Ethereum & $\$ 13,078,527,875$ & $\$ 0.315661$ \\
\hline Bitcoin Cash & $\$ 3,401,381,820$ & $\$ 55.88$ \\
\hline EOS & $\$ 3,283,495,830$ & $\$ 3.62$ \\
\hline
\end{tabular}
}

Source: CoinMarketCap, https://coinmarketcap.com/.

${ }^{3}$ https://eidoo.io/erc20-tokens-list?5a473e2f_page=12. 
Cryptocurrency holders can use the digital asset to buy goods, services, or real currency. According to Hileman and Rauchs (2017), 2.9 to 5.8 million use a cryptocurrency wallet ${ }^{4}$. A number of central banks recently started to explore the adoption of cryptocurrency and blockchain technologies for retail and large-value payments. The People's Bank of China (PBoC) aims to develop a nationwide digital currency based on blockchain technology. The Bank of Canada (BoC) and the Monetary Authority of Singapore (MAS) are studying its use for interbank payment systems. The Deutsche Bundesbank has developed a preliminary prototype for blockchain-based settlement of financial assets. JP Morgan Chase lunched its own cryptocurrency with a fixed value redeemable for one US dollar and no free trade like bitcoin or many other cryptocurrencies.

The most pervasive cryptocurrency is bitcoin (BTC), Satoshi Nakamoto in 2008, and the first bitcoin was "mined" in 2009. Velde (2013) speculated that interest in BTC might be inspired by Hayek's idea (1976) that money should cease to be a state monopoly. However, this link, seems misguided - unlike Hayek's idea. BTC is not issued by private companies in a competitive environment and doesn't maintain a stable value.

The BTC market operates 24 hours a day, 7 days a week ${ }^{5}$. Pricing data is available immediately and free of charge to anyone in the world with Internet. BTC is sold and bought among investors with mathematical algorithms ${ }^{6}$, through BTC's trading companies such as Kraken, Coinbase, Okcoin, etc. Fig.1 shows the relationship between daily Bitcoin price and volume. Bitcoin miners use computer resources to log bitcoin transactions and maintain the blockchain.

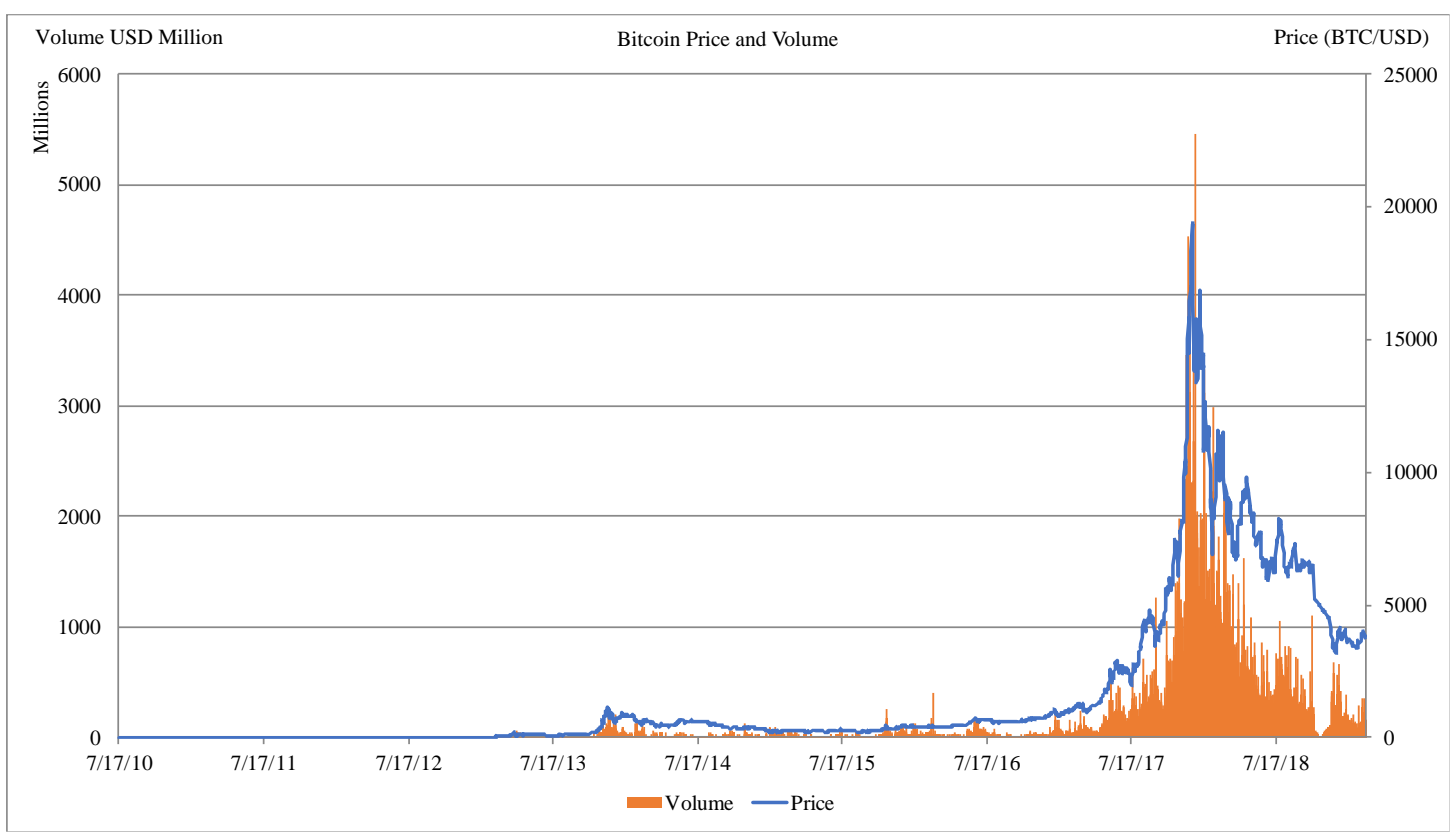

Source: Bitcoinity.org.

\section{Figure 1. Bitcoin Price and Volume}

BTC is made via a mathematical algorithm called "mining." This shows BTC is not fiduciary because real resources such as hardware and energy are expanded in creating BTC. BTC's protocol calls for an eventual end to the mining phase, at which point $k=0$ - Friedman's " $k$ - percent rule" (1960): - the proposal is to fix the annual growth rate of money supply. BTC is scheduled so that the number of BTCs will converge to 21 million units. More preciously, starting with a reward of 50 BTC per block, the supply path is described by $\sum 210,000 \times 50 / 2 i$, which comes to 21 million. Each period $i$ is about 4 years: the upper limits of $21 \mathrm{M}$ BTC is estimated to be reached around the year 2045 .

\footnotetext{
${ }^{4}$ The Bitcoin network experienced a User Activated Hard Fork (UAHF) on August 1, 2017, resulting in Bitcoin "splitting" into two separate cryptocurrencies - Bitcoin (BTC) and Bitcoin Cash (BCH). On this date, Bitcoin Cash was made available to all existing Bitcoin private key owners.

572 exchanges trading 31 currencies were provided by bitcoinchart.com.

${ }^{6}$ According to Yermack (2013), Bitcoin attempts to overcome the weaknesses of both fiat and gold-based money, functioning as an algorithmic currency with deterministic supply and growth rate tied to the rigor of mathematics.
} 
BTC's blockchain consists of a sequence of blocks. Each block builds on its predecessors and contains information about new BTC transactions. The average time between successive BTC blocks is 10 minutes.

BTC's rule is designed by engineers without apparent influence from regulators. The characteristics of BTC is that it operates via peer-to-peer (P2P) technology; it does not have any central authorized financial organization. Transacting and issuing BTC are carried out collectively by the network. Blockchain, the underlying infrastructure and ledger of bitcoin, provides a secure platform for parties to do business with one another (Berentsen and Schar 2018). BIS paper (2018) points out that trust can evaporate at any time because of the fragility of the decentralized consensus through which transactions are recorded.

BTC is a cryptocurrency, without physical representation. BTC aims to be a currency and replace physical currency with a computer file. BTC appears to be a viable rival to the fiduciary currency which does not have intrinsic value but is derived the value by the government fiat and the belief that is accepted by people - in contrast with currencies based on commodity such as gold coins banks notes redeemable in gold.

BTC has multiple legal uses, including purchasing goods and exchanging official currencies granted by various governments (Appendix A). To exchange a currency to another currency (e.g., USD to EUR), consumers are likely to use BTC as a medium because of the low fees compared with private banks. Despite no-permutation rules by governments, BTC has an increasingly important function as a vehicle currency for foreign exchange swaps.

During the event window studied in the progressing bubble and burst (March 2017 to December 2018), I show that the BTC exchange rate is connected to the BTC price volatility. The BTC exchange rate and the official one exhibit deviations of $10 \%$ or more. This addresses not only the low BTC transactions cost of exchanging currency compared to the banking system but also the differences between official exchange rates and BTC ones, which promote arbitrage currency trading among investors. The daily Bitcoin exchange rate with USD shows the no correlation with the USD against other currencies ( EUR, JPY, CHF, GBP, etc.).

The remainder of the paper is organized as follows. Section 2 describes the data collection. Section 3 explains the methodology. Section 4 outlines the results. Section 5 presents a discussion. The last section contains concluding remarks.

\section{Data Collection}

\subsection{Data Collection}

This empirical analysis is based on the daily time series obtained from the data.bitcoinnity.org (beta version) ${ }^{7}$. From these I estimate the unofficial daily BTC exchange rate. Table 1 lists the period, BTC's name and range of BTC exchange rates and official exchange rate: USD/JPY, USD/CNY and EUR/USD. The official exchange rate is from Bloomberg.

Table 1. Exchange Rate

\begin{tabular}{|c|c|c|c|}
\hline Currency & Period & Company & Range \\
\hline \multirow{2}{*}{ USD/JPY } & \multirow{2}{*}{$2015.5 .15-2019.2 .28$} & KraKen & $100.24-130.52$ \\
\cline { 3 - 4 } & & Official & $6.1107-6.9580$ \\
\hline \multirow{2}{*}{ USD/CNY } & \multirow{2}{*}{$2014.7 .24-2017.6 .30$} & Okcoin & $5.6165-7.2776$ \\
\cline { 3 - 4 } & \multirow{2}{*}{ EUR/USD } & Official & $1.0345-1.2548$ \\
\hline & \multirow{2}{*}{$2015.5 .15-2019.2 .28$} & Coinbase & $1.0375-1.2510$ \\
\hline
\end{tabular}

Source: Bloomberg and bitcoinnity.org.

\subsection{Unofficial Exchange Rate}

It is hard to estimate an accurate unofficial and shadow BTC exchange rate, mainly ${ }^{8}$. Assuming that consumers exchange currency on the same trading platform, however, I can estimate the exchange rates, as I now illustrate.

\footnotetext{
${ }^{7}$ The source is https://data.bitcoinity.org/

${ }^{8}$ Investors might not trade within the same BIT company; however, they might use another company if it has a good offer (i.e. a good exchange rate) (See Fig. 2).
} 
Consider a BTC investor exchanging from the Japanese yen to the US dollar via bitcoin, shown in Figure 2. Process of 2 in Fig.2 1) Investors buy the yen BTC using Japanese yen. 2) The yen BTC exchanged for US BTC of the US dollar. 3) The US BTC is exchanged the US dollar. This gives the exchange rate:

$E X=P_{a} / P_{b}$

where $E X$ is the unofficial exchange rate, $P_{a}$ is country A's BTC price, and $P_{b}$ is country B's BTC price.

\section{Three Method of Exchanging Yen to US Dollars}

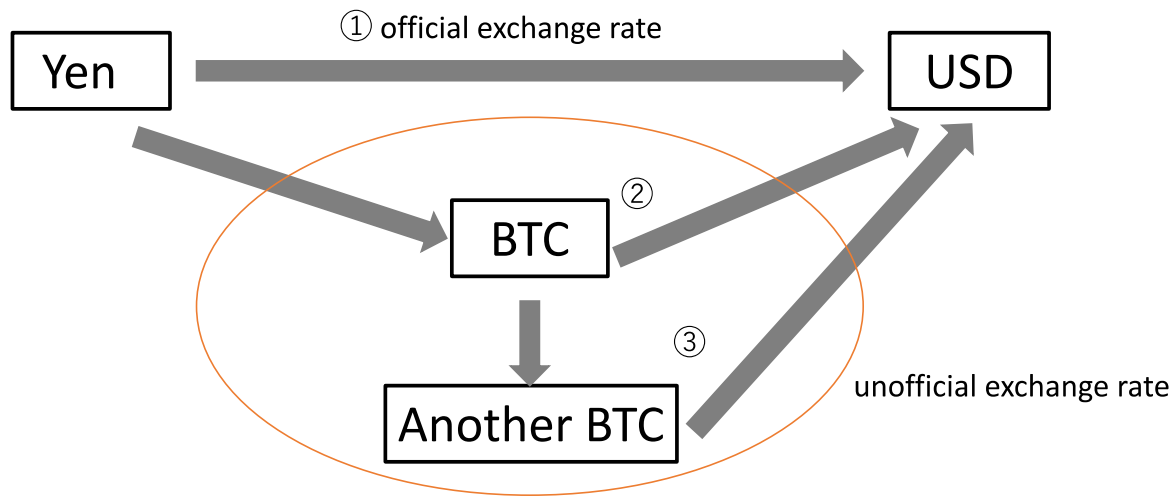

Figure 2. Three Method of Exchanging Yen to US Dollars

Figures 3-1, 3-2, and 3-3 show the unofficial exchange rate and the official exchange rate for 1) USD/JPY, 2) USD/CNY and 3) EUR/USD.

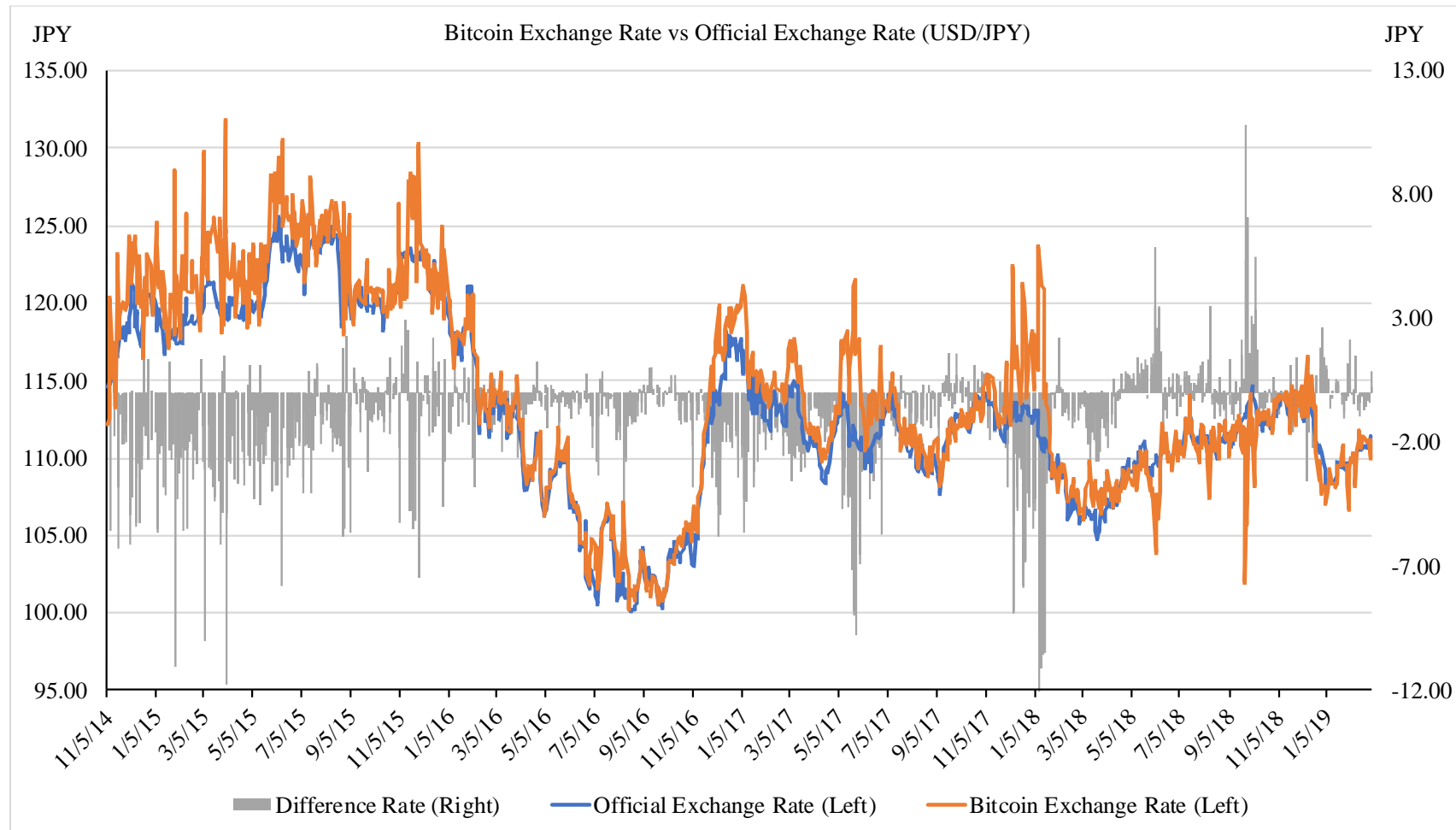

Figure 3.1. Bitcoin Exchange Rate vs Official Exchange Rate (USD/JPY)

Source: Bloomberg and bitcoinnity.org. 


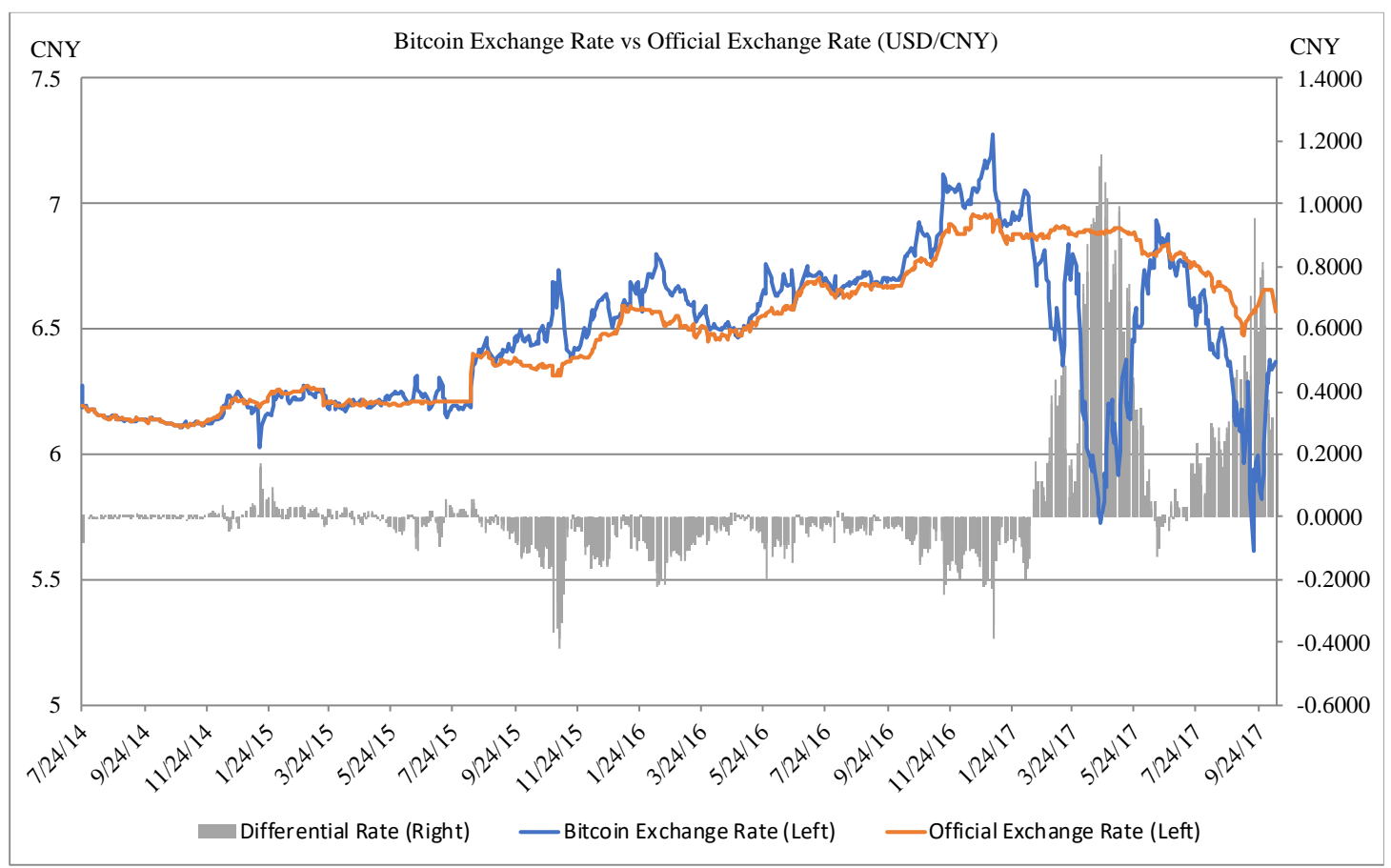

Figure 3.2. Bitcoin Exchange Rate vs Official Exchange Rate (USD/CNY)

Source: Bloomberg and bitcoinnity.org.

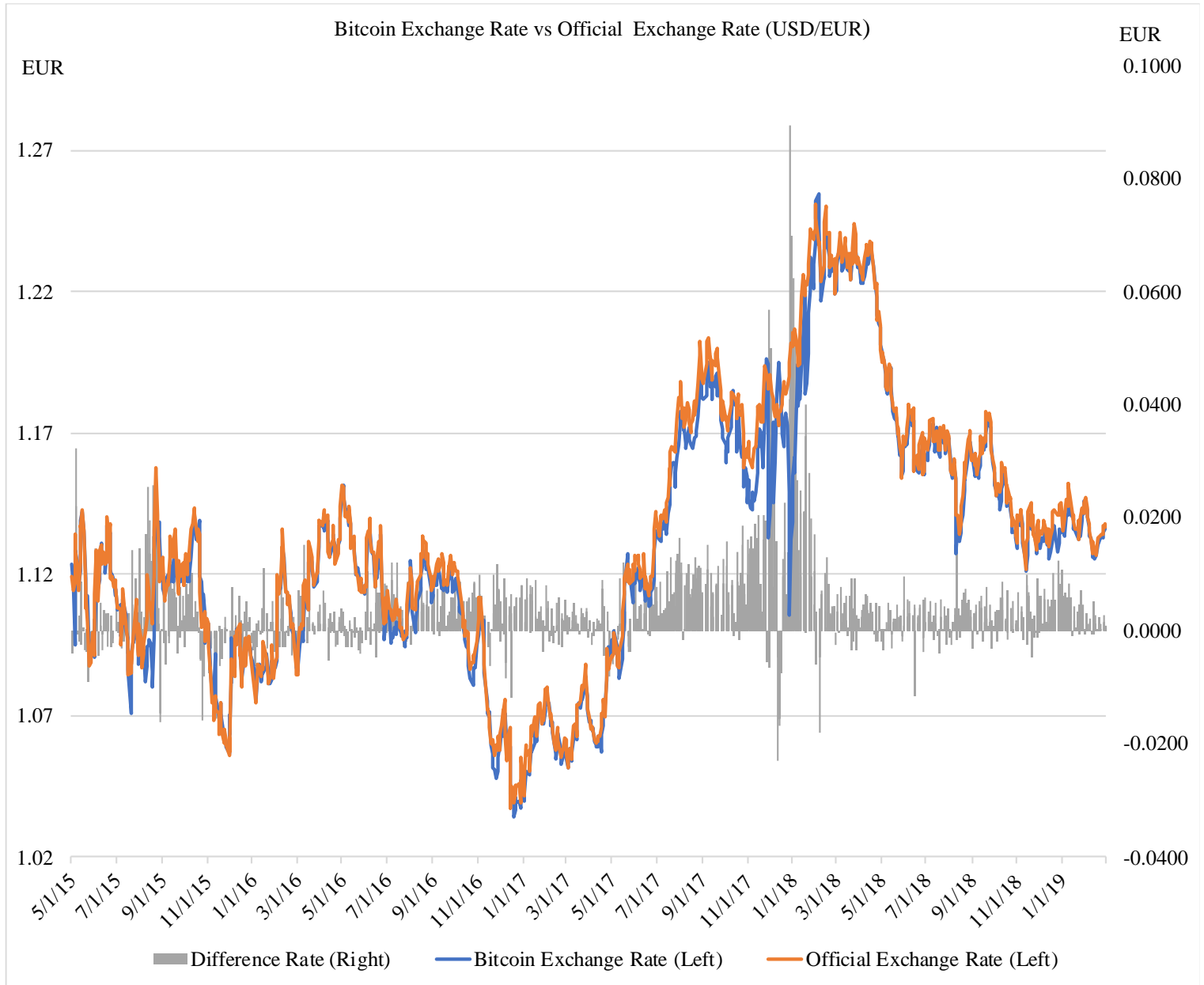

Figure 3.3. Bitcoin Exchange Rate vs Official Exchange Rate (USD/EUR)

Source: Bloomberg and bitcoinnity.org. 


\section{Methodology}

\subsection{Abnormal Return Computation}

The idea of the event window study was published firstly by Dolley (1933). Campbell, Lo and MacKinlay (1997) states the stock price impact against emerging announcements (e.g. a merger). The purpose of the event window study is to measure the abnormal response of an asset price. The model assumes a stable linear relation between the market return and the security return. The abnormal return is the actual ex post return of the security over the event window minus the normal return of the firm over the event window. The normal return is defined as the expected return without conditioning on the event taking place.

To estimate the normal BTC's exchange rates, I use a standard market model where the exchange rates are related linearly to the official exchange rate because Brown and Warner (1985) show 1) simple risk-adjustment approaches perform well in conducting short-run event-window studies and 2) an effective way to detect abnormal performance.

The model for each BTC's exchange rate can be expressed as

$R_{i t}=\alpha_{i}+\beta_{i} R_{m t}+\varepsilon_{i t}$

where $R_{i t}, R_{m t}$ represent the period $t$ price change for BTC's exchange rate and the official exchange rate, respectively, and $\varepsilon_{i t}$ is the residual term with $E\left(\varepsilon_{i t}\right)=0$ and $E\left(\varepsilon_{i t}\right)=\sigma_{\varepsilon}^{2}$. The coefficients $\alpha_{i}$ and $\beta_{i}$ are estimated by running an ordinary least-square regression over the estimation window.

On the other hand, I assume that the estimation window is produced by a change of BTC's price with a new announcement such as restricted trading, hacking and expanding or developing payment systems, etc. As its name implies, the estimation window is used to estimate a model of the BTC's exchange rate under "normal" circumstances. In this paper, however, the new announcement doesn't need to be reflected because the purpose is that there is the comparison between the normal period and the bubble and burst period. BTC's abnormal exchange rate result from the difference between the exchange rate observed during the event period and the expected the exchange rate according to the market model (Eq. (3)):

$\widehat{A R_{l, t}}=R_{i, t}-E\left(\varepsilon_{i, t}\right)$

where $\widehat{A R_{l, t}}$ and $E\left(\varepsilon_{i, t}\right)$ represent the abnormal and expected the exchange rate, respectively, over period $t$ for the exchange rate $i$.

Furthermore, I compute the average abnormal return (AAR):

$A A R_{t}=\frac{1}{N} \sum_{i=1}^{N}\left|\widehat{A R_{l, t}}\right|$

This assumes that the event is exogenous with respect to the change in the official exchange rate. An important characteristic of a successful event study is the ability to identify precisely the data of the event.

The testing procedure this study employs is a t-test, calculated as follows:

$\mathrm{t}-$ test $=\frac{1}{N} \sum_{t=1}^{N}\left|\widehat{A R_{l, t}}\right| /\left|A R_{-} S D\right|$

where number of days refers to the number of days in the event window, AR_SD is the abnormal return standard deviation. The null hypothesis for this analysis is not influenced by random return. That is $H_{0}: \varepsilon_{i, t}=$ 0 or $\sum_{t=t_{1}}^{t_{2}} \varepsilon_{i, t}=0$. According to Kwok and Brooks (1990), using a parametric test is robust enough to detect the presence or absence of abnormal performance.

\section{Empirical Result}

The result of each currency about $\alpha_{i}, \beta_{i}$ which I estimate Eq. (3) is shown in Table 2, and the number of days, average abnormal return (AAR), and t-test of AAR in Table 3. Assuming that the regression residuals are normally distributed, the event window is significant at $95 \%$ compared with the change price of BTCs. 
Table 2. Result 1

\begin{tabular}{|c|c|c|c|c|}
\hline Currency & $\alpha_{i}$ & $\beta_{i}$ & $R^{2}$ & error \\
\hline USD/JPY & -3.422 & 1.037 & 0.91 & 1.85 \\
\hline USD/CNY & 2.646 & 0.596 & 0.43 & 0.19 \\
\hline EUR/USD & -0.018 & 1.019 & 0.97 & 0.08 \\
\hline
\end{tabular}

Source: compiled by author.

Table 3. Result 2

\begin{tabular}{|c|c|c|c|c|}
\hline Currency & Classification & Number of Days & $A A R$ & $t$-test $\%$ \\
\hline \multirow{2}{*}{ USD/JPY } & Normal-AR & 13 & 4.624 & 2.353 \\
\hline & $\begin{array}{c}\text { Bubble \& Burst - AR } \\
(2017.3 .24-2015.12 .15)\end{array}$ & 31 & 6.795 & 3.457 \\
\hline \multirow{3}{*}{ USD/CNY } & Normal-AR & 0 & - & - \\
\hline & $\begin{array}{c}\text { Bubble \& Burst -AR } \\
(2011.3 .25-2017.10 .10)\end{array}$ & 47 & 0.6033 & 3.0299 \\
\hline & $\begin{array}{c}\text { Currency Devaluation } \\
(2015.8 .11-13)\end{array}$ & 0 & - & - \\
\hline \multirow{2}{*}{ EUR/USD } & Normal-AR & 11 & 0.020 & 2.492 \\
\hline & $\begin{array}{c}\text { Bubble \& Burst - AR } \\
(2017.12 .17-2018.12 .15)\end{array}$ & 22 & 0.035 & 4.425 \\
\hline
\end{tabular}

Source: compiled by author.

With regard to the USD/JPY, AAR is higher (6.795) in the processing bubble period than in the normal period (4.624), and the difference is $46.95 \%$ - the index has a link with BTC's price change in the bubble period. Regarding the USD/CNY, the average of the surprise index is also higher in the processing bubble period (0.603), and the index is connected to the price change in the bubble period. The result takes into account the relationship between a new rule for a capital control by PBoC and BTC's price change. On the other hand, in the time of currency devaluation in 2015, there are not gaps between the official exchange rate and BTC exchange rate caused by the event because the BTC market is not bubble and burst. For EUR/USD, there is a relationship between the bubble period and normal period. AAR is higher $(0.035)$ in the processing bubble period than in the normal period (0.020), and the difference is $75 \%$. From these results, I show that the unofficial exchange rate compared with the official exchange rate is more influenced in periods of bubble and burst.

\section{Discussion}

Historically ${ }^{9}$, bubble and burst ${ }^{10}$ occur due to investor behavior. Notorious instances of asset price bubbles include the Dutch tulip mania in Amsterdam (1634-37), the Mississippi Bubble in France (1719-20) and the South Sea Bubble in the United Kingdom (1720). The US. had a real estate bubble in 1816 and a railroad bubble in 1837. Recently, the dot-com bubble was a period of excessive speculation that occurred roughly from 1997 to 2001, and the US-housing bubble occurred in 2006. The bubbles and bursts have occurred at all stages of development: emerging developing, developed financial market, emerging economies. Reinhart and Rogoff (2009) show bubbles have tremendous costs and negative impact not only to the financial system but also to the broader economic system.

The BTC market has also been being experienced bubble and burst. The dollar price of a bitcoin remained under $\$ 1,150$ from its launch in January 2009 until February 22, 2017. BTC reached its peak price of $\$ 19,389.50$ - an exponential increase for about 10 months - at December 17, 2017, as shown in Figure 1. After the peak, the price declined to less than $\$ 4,000$ at end of December, 2018, with its lowest price $\$ 3,212.09$ on

\footnotetext{
${ }^{9}$ See examples: Neal (1990), Neal (2012), Kindleberger (1978), and Shiller (2000).

${ }^{10}$ For example, why is bubble "speculative craze" created again and again? Basically, it is based on the theory of "castle in the air;" a good story about terrific prospects excites investors. Caginalp, Porter and Smith (2001) indicate that stock and other asset prices are influenced by factors beyond the market's realistic assessment of value. The first step is that money flows in and leads cause price appreciation. Additional money is attracted by the prospect of extrapolated higher returns. Demand goes up as the price increases. At some point, the price exceeds the demand increases. At this point, the rising price stopes abruptly; price is no longer any price determined by the demand and supply. Finally, the bubble collapses.
} 
December 15, 2018. Notably, the price action isn't driven by overall market fluctuations compared with the Standard \& Poor's 500 stock index.

To measure whether a bubble is formed, the points where the plot changes to a linear function from a nonlinear function corresponded to the period February 23, 2017 to December 17, 2017. Fig. 4 shows BTC's logarithm scale. Johansen, Sornette and Ledoit (1999) argues that the process of the bubble is described by $P(x) \propto$ $\exp (a t)$ if the bubble is irrational bubble (Appendix B). The plotted value diverges from a linear function when the bubble is created. Shiller (1989) argues that most participants in the stock market follow trends and fashion rather than logical behavior.

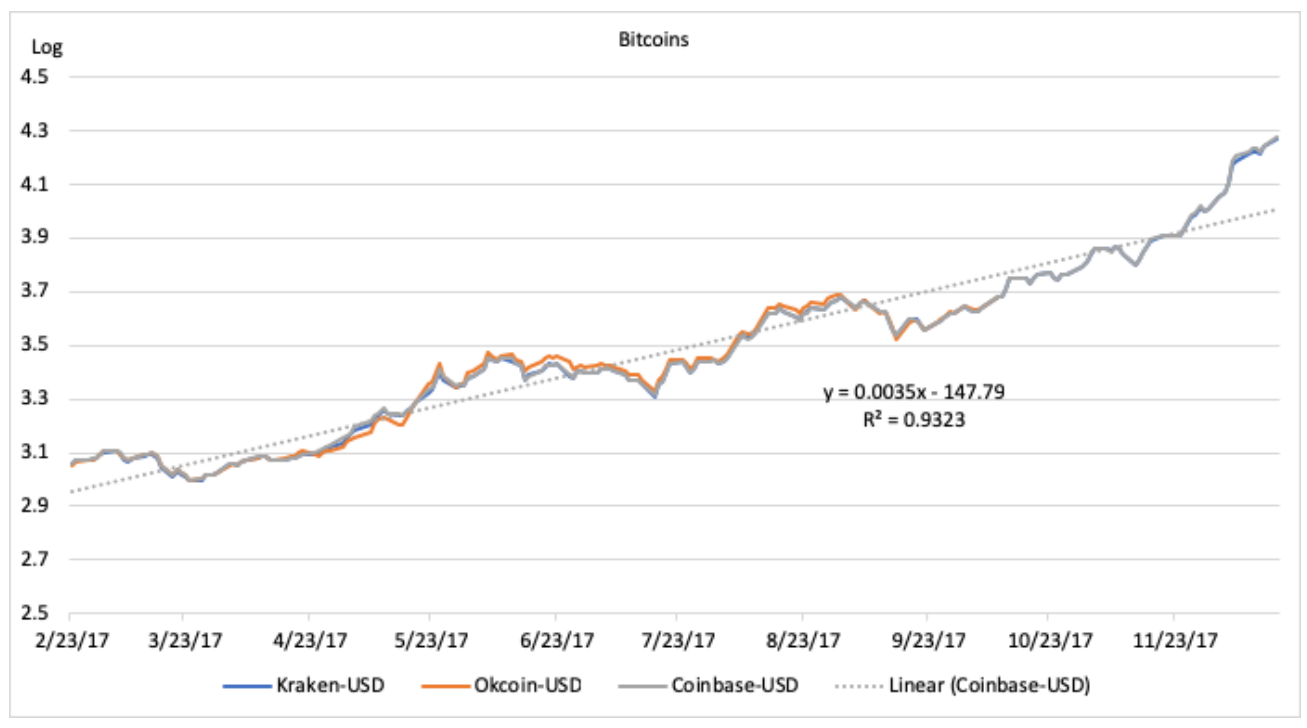

Figure 4. Logarithm of Each Prices

Why is the irrational bubble created again and again? In short, investors' irrational behaviors. According to Fostel and Geanakopls (2012), the US subprime mortgage boom was driven by the financial innovation which was attracting optimistic investors while the burst was driven by the element which was attracting by pessimistic investors. In other words, the subprime mortgage market relied on both buyers and sellers expecting housing prices to go up nationally absent some externally caused depression. Similarly, the advent of blockchain introduced a new financial instrument, bitcoin, which optimistic investors bid up, until the launch of bitcoin futures allowed pessimists to enter the market.

The BTC's price action is connected by a Google searching of "Bitcoin," including investors' psychology Google's trend explorer reveals number of worldwide searches for the keyword "Bitcoin" in Fig. 5 (monthly data). Long-standing speculation suggests there is a positive correlation between the number of Google searches for "Bitcoin" and BTC's price.

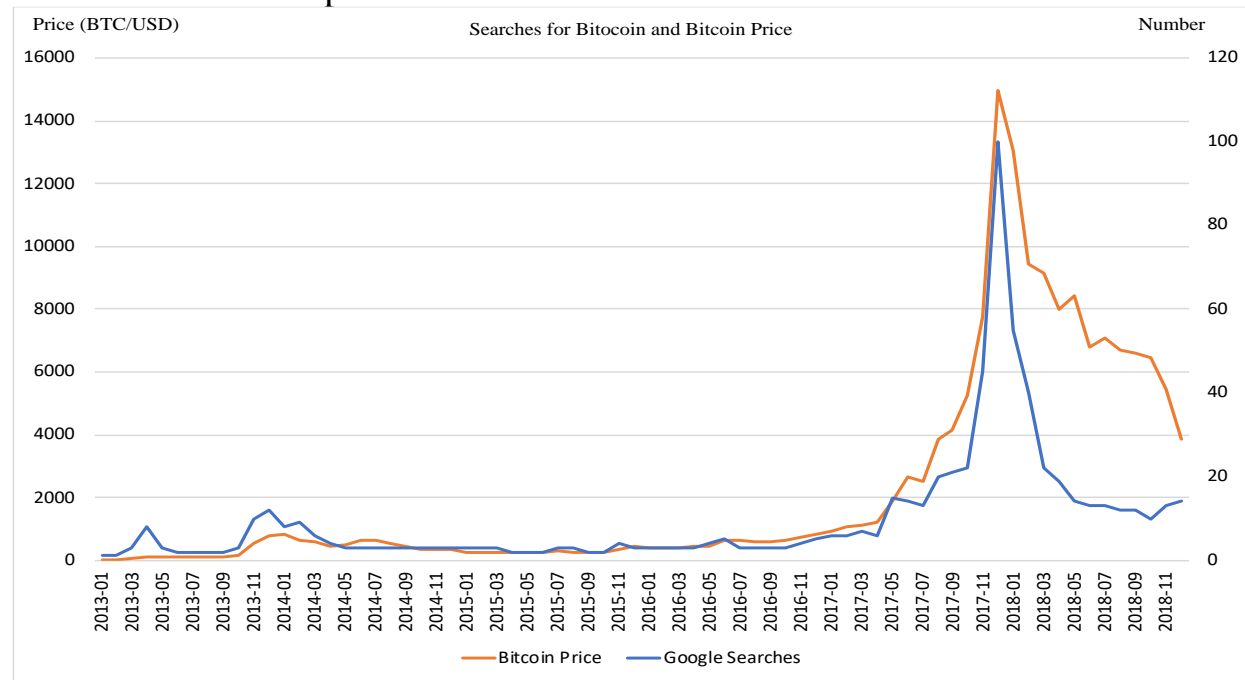

Source: Google and bitcoinnity.org.

Figure 5. Searches for Bitcoin and Bitcoin Price 
Not only the result doesn't show the logarithm scale perfectly although $R^{2}$ is more than 0.93 , but also this time series may be influenced by noise which is not white noise but trend noise (i.e. pink noise) - consecutive price actions such as appreciation or depreciation (see Yoshimori (2019)). If so, I'd need to take into account the rational bubble by Blanchard (1979), Diba and Grossman (1988), and Abreu and Brunnermeier (2003) I finally need to contemplate fundamental values (energy costs, etc.).

\section{Conclusion}

Cryptocurrency like bitcoin (BTC) produced both official and unofficial exchange rates. The main conclusion of this paper is that unofficial exchange rates, particularly USD/JPY, USD/CNY, EUR/USD.

Cryptocurrency advocates will make the same argument about almost all existing currencies like the dollar, yen, euro, franc, pound, etc., which are not convertible into any real commodity. The "fiat currencies" have value because others will take them in exchange and eventually central banks will inflate away this value. Notwithstanding, BTC does not has any fundamental values except for electric energy cost etc.

Cryptocurrencies are new technology-driven financial innovations, and "the progress of the fintech" is a welcome innovation. However, there are different positions. Kaplanov (2012) discusses the need for regulations of the currency free of government intervention, while Carney (2017) says "the FSB (Financial Stability Board) is drawing out supervisory and regulatory issues raised by FinTech from financial stability perspective, informed by a stock take of national authorities' exciting and evolving regulatory approaches to FinTech activities." For financial stability, in my view, regulators have to ensure not only maximize potential benefits to develop fintech but also minimize the potential risks and costs because new technology supports the growth of the economy, reduces economic inequality, and increases financial inclusion to contribute to globalization. As Henry Kissinger stated, "Order should not have priority over freedom. But the affirmation of freedom should be elevated from a mood to a strategy."

BTC has an increasingly important function as a vehicle currency for FX swaps. However, it is hard for the central bank to control the cryptocurrency. As long as there are big differences between official exchange rates and BTC exchange rates, any exchange rate induced by cryptocurrencies ought to be monitored by authorized organizations because of unsustainable price volatility and financial vulnerabilities. Such monitoring could avoid the fear of collapse of the financial system.

\section{Acknowledgements}

Dr. Larry Wall, Federal Reserve Bank at Atlanta, Professor Edward Kane, Boston College, and Mr. Stephen Wolff, Rice University provided their useful comments.

\section{References}

1. Abreu, D. and Brunnermeier, M. K. (2003). Bubbles and Crashes. Econometrica, 71(1), 173-204.

2. Berentsen, A. and Schar, F. (2018). A Short Introduction to the World of Cryptocurrencies. Federal Reserve Bank of St. Louis Review, 100(1), 1-16.

3. Blanchard, O.J. (1979). Speculative Bubble, Crashed and Rational Expectations. Economic letters, 3(4), 387-389.

4. Caginalp, G.; Porter, D. and Smith, V. (2001) Financial Bubbles: Excess Cash, Momentum, and Incomplete Information. The Journal of Psychology and Financial Markets, 2(2), 80-99.

5. Campbell, J.Y.; Lo, A.W. and MacKinlay, A.C. (1997) The Econometrics of Financial Markets. Princeton University Press. 149-180.

6. Carney, M. (2017). Ten Years on: Fixing the Fault Lines of the Global Financial Crisis. Banque de France Financial Stability Review, 21, 13-20.

7. Citi GPS: Global Perspectives \& Solutions. (2016). Digital Disruption - How Fintech is Facing Banking to a Tipping Point, Citi GPS: Global Perspectives \& Solutions. https://www.nist.gov/sites/default/files/documents/2016/09/15/citi_rfi_response.pdf.

8. Diba, B.T. and Grossman, H. (1998). Rational Inflationary Bubble in Stock Prices. The Economic Journal, 98(392), 746-754.

9. Dietz, M.; Khanna, S. Olanrewaju, T. and Rajgopal, K. (2016). Cutting Through the Noise around Financial Technology. New York: McKinsey \& Company. www.mckinsey.com/industries/financial-services/our-insights/cutting-through-the-noise-around-financial-technology 
10. Dolley, J.G. (1933). Characteristics and Procedure of Common Stock Split-Ups. Harvard Business Review, 11, 316-26.

11. Fostel, A. and Geanakoplos, J. (2012). Tranching, CDS, and Asset Prices: How Financial Innovation Can Cause Bubbles and Crashes. American Economic Journal: Macroeconomics, 4(1), 190-225.

12. Friedman, M. (1960). A Program for Monetary Stability. New York: Fordham University Press, p. 90.

13. Kaplanov, N. M. (2012). Nerdy Money: Bitcoin, the Private Digital Currency, and the Case Against its Regulation. Loyola Consumer Law, 25(1), 111-174.

14. Hayek, F. (1976). Denationalisation of Money. London: Institute of Economic Affairs.

15. Hileman, G. and Rauchs, M. (2017). Global Cryptocurrency Benchmarking Study. Cambridge: Cambridge Center for Alternative Finance. https://www.jbs.cam.ac.uk/fileadmin/user_upload/research/centres/alternative-finance/downloads/2017-global-cryptocurrency-benchmarking-study.pdf.

16. Johansen, A., Sornette, D. and Ledoit, O. (1999). Predicting Financial Crashes Using Discrete Scale Invariance. Journal of Risk, 1(4), 5-32.

17. Kindleberger, C. P. (1978). Manias, Panics, and Crashes. A History of Financial Crises. Basic Books.

18. Kim, T. (2015). The Predecessors of Bitcoin and Their Implications for the Prospect of Virtual Currencies. PLOS ONE, 10(4), e0123071.

19. Kwok, C.C.Y. and Brooks, L.D. (1990). Examining event study methodologies in foreign exchange markets. Journal of International Business Studies, 21(2), 189-224.

20. Nakamoto, S. (2008). Bitcoin: A Peer-to-Peer Electronic Cash System. https://bitcoin.org/bitcoin.pdf.

21. Neal, L. (1990). The Rise of Financial Capitalism. Cambridge University Press.

22. Neal, L. (2012). I am Not Master of Events: Speculations of John Law and Lord Londonderry in the Mississippi and South Sea Bubbles. Yale University Press.

23. Reinhart, C. M. and Rogoff, K.S. (2009). The Aftermath of Financial Crisis. American Economic Review, American Economic Association, 99(2), 466-72.

24. Shiller, R.J. (1989). Market Volatility. Cambridge: MIT Press.

25. Shiller, R. J. (2000). Irrational Exuberance. Princeton University Press.

26. Velde, F.R. (2013). Bitcoin: A primer. Chicago Fed letter, No. 317.

27. Yermack, D. (2013). Is Bitcoin a Real Currency? An Economic Appraisal. NBER Working Paper Series, No.19747.

28. Yoshimori, M. (2019). A Phase Transactions of the USD/JPY Exchange Rate with Monetary Policy. Hyperion International Journal of Econophysics \& \& New Economy, 12(1).

\section{Appendix A}

Official money issued by central banks has three function: 1) unit of account, 2) a medium of exchange, and 3) a store of value. Money (cash) meets perfectly these three criteria. On the other hand, BTC hasn't had three functions since it was issued, compared with official money. BTC added another value to original value standard of value. In fact, this function has been being expanded. For instance, consumers can use BTC instead of credit card at online retailers such as Amazon, Dell and eBay. Additionally, the latest bubble would be caused by expanding the store of value. The main factor of the bubble is caused by Japanese investors from January $2017^{11}$.

\section{Appendix B}

Johansen, Sornette and Ledoit (1999) created a model for irrational bubbles. The model doesn't include the interest rate, risk aversion, information asymmetry, or the market-clearing condition. Rational expectations, which are based on fundamentals, are equivalent to the familiar martingale hypothesis:

$\forall t^{\prime}>t E_{t}\left[p\left(t^{\prime}\right)\right]$

where $p(t)$ denotes Bitcoin price at time $t$ and $E_{t}\left[p\left(t^{\prime}\right)\right]$ denotes the expectation conditional $p(t)$ on information revealed up to time $t$.

\footnotetext{
${ }^{11}$ Japanese investors bought bitcoin after January 2017: Sharing of bitcoin trading in major currency (Yen: around 45\%, US dollar: around 35\%, CNY: around 10\%), while CNY: around 90\% was dominated before January 2017 (Source: WSJ on May 27 and 28 , 2017).
} 
If I don't allow the Bitcoin price to fluctuate by white noise, this model distinguishes between the end of a bubble and the time of the crash because the date of the crash has to have randomness.

In the normal (i.e. non-bubble) case, the crash occurs at whenever the market has negative factors which induce a downside.

The cumulative distribution function of the crash is $Q(t)$.

The probability function is

$q(t)=d Q / d t$

The hazard rate, i.e. the probability per unit of time for the next crash is

$h(t)=q(t) /[1-Q(t)]$

For simplicity, assume that during a crash, the price drops by fixed percentage $k \in(0,1)$, say between 20 and $30 \%$ of the price increase above a reference value $p_{1}$. The price before the crash is given by:

$d p=\mu(t) p(t) d t-k p(t) d j$

where $j$ denotes a jump process whose value is zero before the crash and one afterwards, and the time-dependent drift $\mu(t)$ is chosen so that the price process satisfies the martingale condition, i.e.

$\mu(t) p(t)=k\left[p(t)-p_{1}\right] h(t)$

If the crash hazard rate $h(t)$ increases, the return $\mu$ increases to compensate the traders for the increasing risk. Plugging (10) into (9), I obtain an ordinary differential equation. For $p(t)-p\left(t_{0}\right)<p\left(t_{0}\right)-p_{1}$, its solution is

$p(t) \approx p\left(t_{0}\right)+k\left[p\left(t_{0}\right)-p_{1}\right] \int_{t_{0}}^{t} h\left(t^{\prime}\right) d t^{\prime}$ before the crash.

Then I get

$E_{t}[d p]=\mu(t) p(t) d t-k p(t) h(t) d t=0$

This yields:

$\mu(t)=k h(t)$

And the corresponding equation for the price is

$\log \left[p(t) / p\left(t_{0}\right)\right]=k \int_{t_{0}}^{t} h\left(t^{\prime}\right) d t^{\prime}$ 